\title{
UNA LECTURA DE LA FILOSOFÍA DE JUAN RODRÍGUEZ LARRETA
}

\author{
Guillermo HuRTADO
}

Instituto de Investigaciones Filosóficas

Universidad Nacional Autónoma de México

1. Una mañana de invierno de 1981, a la salida de una clase sobre la teoría de las descripciones, Raúl Orayen me platicó sobre su amigo Juan Rodríguez Larreta. Me dijo algo así como: "es un empresario exitoso, pero también un filósofo excelente, algún día tendrás que conocerlo”. Fue en septiembre de 1994, en Buenos Aires, que tuve el privilegio de conocerlo by acquaintance y no solo by description. Cierro los ojos y lo veo como un hombre delgado, de estatura mediana, cabeza grande, cejas muy tupidas, manos pequeñas, elegante desaliño y una candorosa sonrisa. Juan Larreta fue un hombre de una enorme generosidad, sencillez y nobleza. Además fue un filósofo en estado puro; quiero decir, un hombre cuyo interés en las preguntas filosóficas estaba desprovisto de cualquier finalidad ulterior. Hay quienes a través de la filosofía buscan lucimiento, fama o poder. Nada de esto le preocupaba a Juan Larreta. A él solo le importaba - -iy de qué manera! - reflexionar sobre los problemas filosóficos a fondo, sin prisas, sin desplantes. La amplitud de sus intereses, que van de la ontología hasta la ética, de la epistemología hasta la filosofía política, nos da cuenta de su ancho horizonte intelectual. $\mathrm{Su}$ conocimiento de la historia de la filosofía, en especial de la filosofía moderna, también era muy sólido. Larreta tenía una predilección por los argumentos intrincados, las rutas secundarias, las doctrinas heterodoxas. Aunque respetaba los datos de la ciencia, e incluso echaba mano de ellos, tenía una imaginación metafísica muy vigorosa y sutil. Por eso era un placer conversar con él. Sus preguntas y respuestas nunca eran las más obvias, siempre tenían una pizca de sorpresa, de simpático descaro. Sin embargo, nunca dejó de ser un filósofo analítico o mejor dicho: un analítico porteño de la mejor escuela. La claridad y el rigor fueron las divisas de los escritos filosóficos que elaboró durante varias décadas de trabajo discreto y perseverante.

2. Después de su aciago tránsito, en febrero de 2012, sus amigos Tomás Simpson, Nora Stigol e Iñaki Zuberbühler reunieron sus trabajos en un libro que lleva el título de Metafísica, ética y conocimiento. Los veinte artículos están ordenados en cuatro secciones: metafísica, filosofía de 
la mente, teoría del conocimiento y ética y política y están precedidos por una introducción y un poema de Simpson. El libro, publicado por la editorial Prometeo, tiene más de noventa mil palabras, lo que nos da una idea de la actividad filosófica que Larreta realizó de manera paralela a sus demás ocupaciones. Pero me parece que la mayor contribución de este libro es que, más allá de nuestro conocimiento de los artículos aislados de Larreta, de los árboles, nos ofrece la visión del bosque de su filosofía. Y cuando uno tiene el paisaje completo del bosque, incluso si conocía bien algunos de los árboles, no puede dejar de quedar sorprendido por su riqueza.

La mayoría de los trabajos del libro fueron publicados con anterioridad en Análisis Filosófico. Hago una lista: "Cuatro argumentos de Berkeley contra el realismo representativo", "El problema de la justificación en el realismo representativo", "Democracia y moral", "Sobre la privacidad de los estados de conciencia", "La teoría substancialista del espacio y del tiempo y la individuación de particulares”, “Podemos concebir el dolor ajeno sobre el modelo del propio?" y "Testeo, privacidad, y el argumento del lenguaje privado". Varios de los demás trabajos recogidos en el libro fueron publicados en otras revistas y volúmenes colectivos, y no pocos eran inéditos, como: "Sobre un rasgo paradójico del mundo fenoménico", "La identidad de los indiscernibles y el argumento de Adams", "Apuntes acerca del lenguaje privado y la identidad psicofísica", "Valor intrínseco, estado mental y la máquina de Nozick", "Bradley, la polaridad sujeto-objeto y la elusividad sistemática del yo", y "Apuntes de metaética".

Los trabajos de metafísica se ocupan primordialmente del problema de la individuación; los de filosofía de la mente, sobre el tema de la privacidad de lo mental; los de teoría del conocimiento, sobre el problema de la representación; y los de ética y filosofía política sobre diversas cuestiones de estas áreas.

Si bien la organización temática de los artículos facilita la lectura del volumen, me parece que se pudo haber elegido otro orden que resaltara su cronología, o mejor dicho, su genealogía. En lo que sigue haré una lectura del libro que tomará una ruta diferente. Esta lectura es personal, no solo porque toda lectura acaba siéndolo, sino porque se intercala con mi propia trayectoria filosófica, que, como se verá, coincidió con la de Larreta en algunos momentos.

3. El punto de partida de la lectura que haré de la obra filosófica de Larreta es su artículo "Sobre la privacidad de los estados de conciencia" de 1987. Como se verá, de este ensayo parten varias de las líneas de 
investigación que él desarrolló con posterioridad tanto en filosofía de la mente como en metafísica.

En ese trabajo, escrito junto con la psicoanalista Beatriz Dorfman, se propone algo que para algunos filósofos tan distinguidos como Alfred Ayer era sencillamente inconcebible, a saber, que la tesis de la privacidad de lo mental no solo no es analíticamente verdadera, sino que es posible que sea empíricamente falsa. Larreta comienza por mostrar que la tesis de la analiticidad de la tesis de la privacidad de lo mental está basada en dos supuestos que no han sido probado por sus defensores: o bien que la relación entre el sujeto y las vivencias es de una naturaleza tal que torna imposible que dos sujetos tengan de manera simultánea una misma vivencia, o bien que las relaciones que guardan entre sí las vivencias simultáneas torna imposible que una misma vivencia pertenezca al mismo tiempo a dos mentes distintas. Sin embargo, no hay en la literatura sobre la privacidad de lo mental argumentos a favor de estos dos supuestos.

Pero más allá de si podemos defender de manera analítica o a priori la tesis de la privacidad, hay algunos casos, muy inusuales pero no por eso empíricamente inviables, de contraejemplos de dicha tesis. Larreta ofrece un caso hipotético tomado de Paul Meehl:

Imaginemos dos seres humanos cuyos cráneos están unidos de manera tal que tienen en común la corteza visual. Dichos siameses compartirán aquellos procesos cerebrales que constituyen las contrapartidas físicas de las sensaciones e imágenes visuales. Pero siendo así, el que acepte la tesis del isomorfismo psicofísico, tendrá que admitir que ambos siameses comparten también sus sensaciones e imágenes visuales, dado que los procesos psíquicos correspondientes tendrán también, ya que hay una relación de isomorfismo, una parte en común. Ahora bien, este ejemplo choca prima facie con la tesis de la privacidad, puesto que habría dos mentes (a cada uno de los siameses le corresponde una mente distinta) que experimentarían las mismas sensaciones e imágenes visuales. (Rodríguez Larreta 2013, pp. 117-118).

Para defender la tesis de la privacidad habría que defender una teoría holística de la mente según la cual la totalidad de las vivencias en un momento dado constituyeran un "todo orgánico", donde cada una de ellas estuviera vinculada constitutivamente con todas las demás. En ese caso, se sigue que dos mentes distintas no puedan compartir una y la misma vivencia en un momento dado. Pero para responder al caso de los siameses, se requiere más que una teoría holística de la mente. Larreta 
sostiene que o bien se rechaza la tesis del isomorfismo psicofísico, con lo cual el ejemplo se vuelve irrelevante, o preservamos la tesis del isomorfismo psicofísico y nos comprometemos con una teoría holista que incluya los procesos cerebrales correlativos a los fenómenos conscientes.

Larreta opina que la opción de abandonar el isomorfismo psicofísico es demasiado costosa, por lo que es preferible considerar la segunda opción. Para ello, habría que postular una diferencia de niveles, de modo que las propiedades del nivel consciente asociadas con la parte cerebral común estén determinadas por la totalidad de cada cerebro y no solo por la parte común. Sin embargo, esta opción también le resulta costosa y compleja. La conclusión del artículo es que la tesis de la privacidad de lo mental no solo no es trivialmente verdadera, sino que para sostenerla hay que asumir compromisos filósofos muy debatibles. La balanza se inclina, por lo tanto, hacia el rechazo de dicha tesis.

4. Hago una pausa en mi lectura de la obra de Larreta para contar algo sobre nuestro diálogo filosófico en torno al tema de la privacidad.

En 1994, el mismo año en el que lo conocí, publiqué en Crítica un ensayo intitulado "Subjetividad y Privacidad" en el que, por medio de experimentos mentales inspirados en la obra de Parfit, sostenía la posibilidad de que dos personas tuvieran uno y el mismo estado mental. La conclusión a la que llegaba era que la privacidad no era una condición necesaria de la vida mental, prácticamente la misma a la que, sin saberlo yo, había llegado Larreta en "Sobre la privacidad de los estados de conciencia".

Poniendo a un lado mi negligencia por no haber leído su trabajo -vicio común entre los analíticos latinoamericanos, aunque ello no me exima de la culpa - esta coincidencia nos hizo cómplices en el rechazo de un doctrina casi universalmente aceptada y, como era de esperarse, fortaleció nuestra amistad, porque si algo une a dos personas es sentir que pertenecen a una cofradía de solo dos miembros. Sobre este tema y sus derivaciones hablamos a lo largo de los años. Por eso, si me lo permiten, diré algo sobre mi propuesta.

El argumento que yo ofrecía en mi artículo era más ambicioso que el de Juan, ya que evadía la objeción holista. Me explico. Si es posible una fusión temporal de dos corrientes de conciencia, entonces, en ese momento dos personas tendrán todas y cada una de las vivencias en común. Es decir, en un momento dado la totalidad de los estados mentales de la persona A y B sería la misma. Sin embargo, mi argumento descansaba

${ }^{1}$ Hurtado (1994). 
sobre un supuesto más debatible, el de la fusión de conciencias, por lo que era más débil que el de Juan.

La posibilidad que examinaba en mi artículo dejaba como un enigma cómo puede haber dos personas y un mismo sujeto consciente en un tiempo dado. La conclusión a la que llegué es que teníamos que distinguir entre las nociones de sujeto y de persona. Este corolario me llevó a dedicarme al tema de la metafísica de la persona durante varios años. En "Sujeto, persona y sentido" ${ }^{2}$ desarrollé las consecuencias de la distinción entre persona y sujeto. Sin embargo, en "Cómo convertirse en otra persona sin dejar de ser uno mismo"3 omití por completo la noción de sujeto y reformulé la distinción como una entre la persona y el ser humano que cada uno es. Lo que me pareció entonces - y sigo creyendo hoy- es que todos los argumentos basados en los ejemplos de fusión y fisión de Parfit carecían de solidez, o mejor dicho, que eran escenarios ficticios que no nos dicen cómo usar el concepto de persona en la vida real. Sin embargo, la distinción entre la persona y el ser humano que cada uno es me parecía, y me sigue pareciendo, que nos permite entender mejor nuestras vidas atribuladas y breves.

Pero mientras que el rechazo de la tesis de la privacidad de lo mental me llevó a consideraciones sobre metafísica de la persona, Juan Larreta tomó otras rutas. Veamos cuáles fueron.

5. Al final de "Sobre la privacidad de los estados de conciencia", Larreta ofrecía algunas consecuencias de la falsedad de la tesis de la privacidad. Menciono dos de ellas: la primera es que lo mental sería tan público como lo físico, la segunda es que las todas críticas a la psicología introspeccionista basadas en el carácter privado de los fenómenos mentales serían infundadas.

Estos dos corolarios de su rechazo de la tesis de la privacidad de lo mental lo motivaron a efectuar una revisión crítica de los argumentos wittgenstenianos sobre el lenguaje privado. Esta labor la realizó en tres artículos: "Apuntes acerca del lenguaje privado y la identidad psicofísica", “¿Podemos concebir el dolor ajeno sobre el modelo del propio?” y "Testeo, privacidad y el lenguaje privado".

En el primero de esos artículos, que en realidad se trata, como indica el título, de apuntes, Larreta señala, basándose en trabajos previos de Strawson y Castañeda, que el argumento de Wittgenstein tiene tres problemas. El primero es que no solo niega la existencia de un lenguaje

\footnotetext{
${ }^{2}$ Hurtado (2001)

${ }^{3}$ Hurtado (2009).
} 
de sensaciones sino de cualquier lenguaje que no pueda ser testeado intersubjetivamente, como por ejemplo, el de Robinson Crusoe. El segundo es que rechazar el autotesteo tiene consecuencias demasiado fuertes para nuestro conocimiento fundado en la memoria. El tercero es que si la autocorrección es factible por parte de un hablante de un lenguaje privado, la imposibilidad de ser corregido por otros hablantes no puede ser un impedimento para la existencia de dicho lenguaje.

Estos apuntes, que hasta ahora estaban inéditos, son un antecedente del artículo "¿Podemos concebir el dolor ajeno sobre el modelo del propio?" publicado en 2005. En este artículo se distinguen, siguiendo a Malcolm, dos argumentos wittgenstenianos contra el lenguaje privado. El primero, apodado "interno", cuestiona los supuestos en los que se basaría dicho lenguaje; el segundo, apodado "externo", intenta mostrar las consecuencias implausibles de aceptar dicho lenguaje. Larreta expone las objeciones de Kripke al argumento externo, pero además ofrece razones para suponer que podemos concebir experiencias de otros. Con base en los ejemplos de Parfit y de otros autores basados en la posibilidad de fusiones y fisiones mentales, se muestra que el argumento externo de Wittgenstein pierde fuerza, ya que podemos concebir experiencias pasadas que pertenezcan a otros personas y que serían recordadas "desde dentro".

En "Testeo, privacidad y el argumento del lenguaje privado", publicado en 2009, Larreta amplía su ataque al argumento del lenguaje privado de Wittgenstein. Ofrece tres objeciones al argumento "interno". Las dos primeras cuestionan la premisa de que un lenguaje de sensaciones no podría testearse. La tercera objeción, la más fuerte, consiste en que las sensaciones no son esencialmente privadas. Si bien se cita el antecedente de su artículo "Sobre la privacidad de los estados de conciencia", Larreta nos ofrece un ejemplo diferente al de los siameses. Se trata de una bisección cerebral gradual en la cual el sujeto estuviese consciente. Lo que se nos plantea es el caso de una bisección en la cual el centro del dolor fuese compartido momentáneamente por dos sujetos de conciencia.

A la distancia, me parece que el ataque de Larreta a Wittgenstein tendría que sopesarse a la luz de una distinción entre dos nociones de privacidad. La primera, que he llamado privacidad-1 considera que si algo es privado lo es en relación a uno y solo un referente. La segunda, que he llamado privacidad-2, afirma que si algo es privado, lo es en relación a un conjunto restringido de referentes - este es el sentido de "privado" en el que decimos que un club es privado-. Los argumentos de Larreta van en contra del supuesto de que no puede haber un lenguaje privado1. Pero creo que podemos encontrar razones para rechazar el supuesto 
de que el modelo de nuestro lenguaje es compatible con la privacidad-2. Uno de ellos es el argumento de Donald Davidson de que no puede haber lenguajes intraducibles. Me parece que, al no distinguir entre estas dos nociones de privacidad, Larreta desatiende la intuición que está en el fondo del argumento de Wittgenstein del lenguaje privado. Por otra parte, hoy pienso que los ejemplos de siameses, fisiones y fusiones son anomalías, casos límite que solo se entienden desde el marco conceptual que nos ofrece un lenguaje público. Ya no creo que ese sea el método correcto para hacer filosofía. Por ello, las conclusiones a las que yo mismo llegué siguiendo aquel método me parecen cuestionables.

6. Hemos visto cómo el artículo de Larreta "Sobre la privacidad de los estados de conciencia" es el detonador de sus trabajos posteriores en filosofía de la mente. Como veremos ahora, aquel artículo también es un antecedente de algunos de sus trabajos en metafísica.

Una consecuencia de que pueda haber dos sujetos en un mismo cuerpo es que estarían en un mismo punto espacio-temporal. Esta consideración lleva a Larreta a escribir su artículo "La teoría substancialista del espacio y del tiempo y la individuación de particulares".

En ese trabajo, publicado en 1998, examina la tesis de que el espacio-tiempo está compuesto de puntos o instantes que pueden existir aunque no haya nada material o mental en ellos. Desde esta concepción, el espacio-tiempo es como un cuadriculado que contiene casilleros que pueden estar vacíos, pero que, si no lo están, sirven para individuar a los objetos que están dentro de ellos, puesto que cada uno de ellos se distingue de manera numérica de cualquier otro. Se ofrecen tres argumentos en contra de esta teoría. Los tres coinciden en mostrar que la diferencia solo numero está presupuesta por la teoría y, por lo tanto, la diferencia de posición espaciotemporal no fundamenta la supuesta diversidad numérica de particulares indiscernibles. Pero al final de su trabajo, Larreta afirma que otra razón importante para no aceptar la teoría en cuestión es que puede haber dos particulares que no difieran en posición espaciotemporal, por ejemplo, dos mentes cartesianas simultáneas. Aunque en este artículo Larreta considera la posibilidad poco digerible de dos mentes cartesianas que ocupan la misma área del espacio y tiempo — digamos, una glándula pineal en condominio-, es claro que el caso que tenía en mente es el que había planteado nueve años atrás en su artículo en contra de la tesis de la privacidad. Esto quedó manifiesto en su trabajo posterior "La identidad de los indiscernibles y el argumento de Adams". 
En ese texto, Juan examina un argumento en Adams en contra de la identidad de los indiscernibles que no está sujeto a las críticas que él había hecho a esta posición en "La teoría substancialista del espacio y del tiempo y la individuación de particulares". El argumento se basa en la intuición de que la diversidad numérica de dos particulares no puede verse afectada por la desaparición de una diferencia cualitativa ínfima entre ellos. Adams considera el caso de dos mentes cuya única diferencia es que, al mismo tiempo, una sueña con un monstruo de siete cuernos y otra con uno de diez cuernos. Dado que la desemejanza entre ambas mentes es minúscula, si desapareciera no afectaría la diversidad numérica de aquellas mentes, por lo que, se concluye, podría haber un mundo con dos mentes totalmente indiscernibles. Larreta tenía una buena opinión de este argumento, pero debo decir que a mí me parece una petición de principio disfrazada y, además, me recuerda ese chocante dicho mexicano que reza "qué tanto es tantito...". Pero lo importante en este caso es que Larreta sostiene que si rechazamos la tesis de la privacidad de lo mental, la conclusión de Adams se tambalea, ya que podríamos simplemente decir, volteando el ejemplo, que las dos mentes se fusionan en una sola después del sueño. En este trabajo, Juan vuelve a exponer las mismas objeciones a la tesis de la privacidad que había ofrecido en trabajos anteriores, aunque ahora distingue entre una variante fuerte y una débil, atribuyéndome la crítica de la variante que él denomina fuerte.

Larreta desarrolló su defensa de la identidad los indiscernibles en otros artículos, pero no me ocuparé de ellos aquí. Tampoco diré nada de sus trabajos sobre el realismo, la naturaleza del yo o de los que abordan cuestiones de ética y filosofía política. Atención especial merecería su ensayo "Espacio, tiempo y memoria" de 2007. Este admirable ejercicio de reflexión es la última palabra de Larreta en metafísica. Defiende un monismo inmaterialista según el cual todo lo que existe es de la misma categoría que los campos de conciencia, reduciendo el espacio-tiempo a relaciones internas. El examen cuidadoso de esta teoría me obligaría a extenderme demasiado, por lo cual dejaré esa tarea para otra ocasión. En particular, me interesaría comparar esta metafísica con otra de sello leibniziano, la teoría de las guisas de Castañeda.

Mi objetivo aquí ha sido modesto: mostrar una línea de continuidad de ciertas intuiciones a lo largo de la obra filosófica de Larreta. Esta continuidad, extendida a lo largo de dos décadas, no se expresó en la forma de un sistema filosófico, pero se puede decir que él tenía los elementos para amalgamar sus escritos de esa manera. Aunque no le dio tiempo de construir ese sistema, sí podemos hablar, con toda justicia, de la filosofía de Juan Larreta, es decir, de una obra personal, original y valiosa. 
Cuando acabé la lectura de Metafísica, ética y conocimiento pensé que debí haber buscado a Juan con más frecuencia para conversar sobre filosofía. No solo hubiera encontrado solaz en esas pláticas, sino que también hubiera aprendido mucho de ellas. No me queda más que llevarme sus escritos a mi torre e imaginar los diálogos que ya jamás tendremos de este lado de la orilla.

\section{Bibliografía}

Hurtado, G. (1994), "Subjetividad y privacidad”, Crítica, 26 (76/77), pp. 185-203.

(2001), "Sujeto, persona y sentido", en Pinheiro, U., Ruffino, M. y Junqueira Smith, P. (comps.) (2001), Ontologia, conhecimento e linguagem, Rio de Janeiro, Mauad Editora.

(2009), Por qué no soy falibilista, México, Los libros de Homero.

Rodríguez Larreta, J. (2013), Metafísica, ética y conocimiento, Buenos Aires, Prometeo.

Recibido el 14 de noviembre de 2013; aceptado el 18 de marzo de 2014. 